\title{
SOBRE EL “ENCUENTRO DE GEÓGRAFOS DE AMÉRICA LATINA”. ENSAYO DE APROXIMACIONES TEÓRICAS EN TORNO A UN NOMBRE
}

\section{ON THE "MEETING OF GEOGRAPHERS OF LATIN AMERICA". ESSAY OF THEORETICAL APPROACHES AROUND A NAME}

\author{
Emilas Darlene Carmen Lebus ${ }^{1}$
}

Fecha de recepción: 03-08-2020

Fecha de aceptación y versión final: 06-04-2021

\section{Resumen}

Este ensayo analiza el pretendido (y ya concretado) cambio de nombre del reconocido evento científico: Encuentro de Geógrafos de América Latina. El énfasis está puesto en el nuevo nombre y sus implicancias. Su contenido pivotea en la relación entre el nombre y la cosa representada: lo que subyace, esconde o encripta detrás de un nombre. Se trata de un abordaje semiótico, con ribetes cognitivo-epistémicos, que lo diferencia de otras posturas.

El enfoque conceptual abreva en las ciencias cognitivas, la semiótica y la epistemología, utilizando categorías analíticas provenientes de campos transdisciplinarios con potencia iluminadora hacia las ciencias particulares, en este caso la geografía, para interpretar el cambio de nombre del citado evento. Se propone re-centrar la discusión en el objeto formal de la geografía, considerando sus fundamentos lógico-ontológicos, cognitivos y semióticos desde dicho enfoque, distinguiéndolo de las intencionalidades discursivas de sus cultores y sin descuidar un criterio amplio de la noción de sujeto cognoscente.

Se plantean las implicancias educativas del tema y como conclusión principal se enfatiza la necesidad de una discusión más profunda del sentido del cambio propuesto, que considere el sustento semiótico del tema y sus derivaciones formativas (educacionales), y recupere los fundamentos teóricos de la ciencia geográfica, la ontología de su objeto y su acervo investigativo sin soslayar los contextos actuales, dada la significatividad de los EGAL para el desarrollo de la geografía en el contexto latinoamericano.

Palabras clave: geografía - EGAL - nombre y cosa nombrada - semiosis.

\section{Abstract}

This essay analyzes the intended (and already concretized) name change of the renowned scientific event: Meeting of Geographers of Latin America. The emphasis is on the new name adopted and its implications.

Its content pivots on the relationship between the name and the thing represented: what underlies, hides or encrypts behind a name. It is a semiotic approach, with cognitive-epistemic edges, which differentiates it from other positions. The conceptual approach draws on the cognitive sciences, semiotics and epistemology, using analytical categories from transdisciplinary fields with illuminating power towards the particular sciences, in this case the geography, to interpret the name change of the aforementioned event. It is proposed to re-center the discussion on the formal

${ }^{1}$ Doctora en Ciencias Cognitivas. Magister en Epistemología y Metodología de la Investigación Científica. Profesora y Licenciada en Geografía. Docente e Investigadora en la Facultad de Humanidades, Universidad Nacional del Nordeste (UNNE), República Argentina. Sus campos de interés: geografía, epistemología, metodología, semiótica y ciencias cognitivas. Correo electrónico: emilaslebus@gmail.com/ emilaslebus@ hum.unne.edu.ar ORCID: 0000-0002-9456-8742. 
RIIE (2021), Año 12 (15), 1-26.

DOI: http://dx.doi.org/10.30972/riie.12155565
Sobre el "Encuentro de Geógrafos de América Latina”. Ensayo de Aproximaciones Teóricas en torno a un Nombre.

object of geography, considering its logical-ontological, cognitive and semiotic foundations from said approach, distinguishing it from the discursive intentions of its cultivators and without neglecting a broad criterion of the notion of cognitive subject.

The educational implications of the topic are raised and as the main conclusion the need for a deeper discussion of the sense of the proposed change is emphasized, which considers its semiotic support and its formative (educational) derivations, and recovers the theoretical foundations of geographical science, the ontology of its object and its research heritage without ignoring current contexts, given the significance of EGALs for the development of geography in the Latin American context.

Key words: geography - EGAL - name and named thing - semiosis. 
RIIE (2021), Año 12 (15), 1-26.

DOI: http://dx.doi.org/10.30972/riie.12155565
Sobre el "Encuentro de Geógrafos de América Latina”. Ensayo de Aproximaciones Teóricas en torno a un Nombre.

"El mapa no es el territorio"

(Korzybski, 1994)

\section{Introducción}

Este trabajo tiene su génesis, prima facie, en el pedido que, a fines de 2019, me hiciera el Departamento de Geografía de la UNNE: que elabore un escrito de base para argumentar la posición del citado Departamento ante el inminente interés -entre profesionales de la geografía- de cambiar el nombre a uno de los clásicos eventos científicos que reúne a sus cultores en el continente americano. Me refiero al "Encuentro de Geógrafos de América Latina", más conocido por su sigla EGAL, denominación originaria, usada hasta el presente.

Esta motivación inicial me condujo a explorar el asunto desde conceptos, categorías de análisis e ideas de índole cognoscitiva y epistémica, encarando el tema desde una fundamentación cimentada en lo general, en concordancia a la línea planteada por Morin (2001'); esto es, considerando los "asuntos medulares" para el futuro de la humanidad y a la vez convencida que sólo un posicionamiento metacognitivo puede arrojar luz en esta dirección. En este ensayo me adentro pues a tratar ideas desde el pensamiento general, abriendo paso a una mirada transdisciplinaria al reflexionar sobre la temática.

El enfoque conceptual que nutre esta discusión proviene de las ciencias cognitivas, entendiendo la cognición desde un punto de vista "ampliado"; línea que interpreta los procesos cognitivos como fenómenos semióticos o comunicacionales vinculados a la regulación de la vida (incluida la vida social humana) en todas sus formas. Samaja (2007) vincula esta instancia de desarrollo de las ciencias cognitivas con el enfoque transdisciplinario de la cognición. Desde este criterio, la propia noción de "sujeto cognoscente" se resignifica, para incorporar distintas dimensiones del sujeto y diferentes fuentes en la construcción del conocimiento. Los múltiples "modos del conocer" (caminos cognoscitivos) convergen en el modo científico de conocimiento; si bien cada uno de estos recorridos supone -como sostiene Peirce (1988)ii- distintas formas de "fijación de creencias", el método de la ciencia los subsume y articula.iii

Ahora bien, el objeto o tema central del ensayo no radica simplemente en el cambio de nombre del evento mencionado, sino también en el análisis -desde las ciencias cognitivas y la semiótica- de aquellos asuntos que son inherentes a una ciencia, en especial cómo se define y entiende su objeto de estudio. La categoría de "objetomodelo", propuesta por Samaja (1995) iv resulta a este respecto muy fecunda, pues entronca con la construcción (modelización) de un campo disciplinar. Por ello, las ideas que desarrollo están ancladas en un enfoque ontológico-formal del objeto de la geografía, esto es, el espacio geográfico. Dicha modelización se realiza no sólo desde ciertas categorías del pensamiento, sino también -e inevitablemente- desde un posicionamiento epistemológico, o sea, de cierta manera de entender la ciencia y practicarla.

Asumo que la cuestión ontológica-cognoscitiva que se esconde detrás de un nombre no es un asunto "limitado" a la discursividad, como si ésta operase por fuera de cierto contenido del pensamiento (es decir, en tanto objeto pensable / pensado). Por el contrario, el discurso es la expresión más tangible de la dimensión pragmática del signo que participa en ese proceso de modelización. Pero esta pragmática de la discursividad no puede prescindir de las dimensiones sintáctica y semántica del signo, como bien lo ha advertido Parret (1993), porque, de lo contrario, la semiosis misma quedaría 
totalmente desvirtuada convirtiéndose, en el caso que nos ocupa, en una "pragmática perversa". ${ }^{\circ}$

Por ello, en este ensayo busco poner de relieve aquello que subyace o se oculta -pero exige develarse- detrás de un nombre. Esta tarea, por cierto, está ligada a las prácticas del discurso, pero asimismo a los supuestos epistemológicos sobre una ciencia, la ontología subyacente al objeto y las categorías que empleamos para conocerlo. De ahí su convergencia con un enfoque semiótico-cognitivo, cimentado a su vez en la reflexión teórica. En consecuencia, el objetivo primario (e inmediato) es identificar y señalar las razones de peso que ameritan ser tenidas en cuenta en un posible cambio de denominación del citado evento, proporcionando los fundamentos que hacen al objeto de la ciencia, en torno al cual convergen los múltiples recorridos y acciones (métodos, estrategias de estudio y técnicas de análisis) que participan en su conocimiento.

Ligado a ello, el objetivo principal (y quizás más mediato) de esta reflexión teórica es sentar ideas de base sobre los aspectos que están en el trasfondo de la cuestión, a fin de que éstos puedan ser retomados en futuros debates sobre el tema. En última instancia se trata de recuperar la dimensión ontológico-cognoscitiva de la ciencia, sin deslizar (o evitar) -en el cambio terminológico- los fundamentos y la esencia misma de la geografía hacia intereses políticos o de grupos sociales activistas embanderados con una posición ideológica "particular" (como ocurre, en el contexto actual desde el cual se propicia el cambio de nombre del citado evento, con la postura feminista y de la perspectiva de género, tan en boga en estos momentos). ${ }^{\text {vi }}$

La exacerbación de estos posicionamientos ideológicos que están en el trasfondo del cambio de nombre del evento que nos ocupa conduce a un reduccionismo del pensamiento, pues, explorando la literatura afín a las posturas que impulsan el cambio de nombre del EGAL, se identifican construcciones discursivas de rechazo, desvalorización y negación del saber geográfico generado y acumulado en la historia de la geografía. Empero, o toda ciencia es "plural" (en el auténtico sentido de la expresión y no mera proclamación que luego en las acciones -sobre todo en la práctica investigativa- queda vacío de contenido y/o de consistencia), o bien no es nada, porque una ciencia mutilada del ejercicio reflexivo y autocrítico deja de ser emancipadora y se convierte en esclava de los poderes de turno (de cualquier naturaleza). Por esta razón, frente a toda pretensión hegemónica es preciso ofrecer una postura alternativa, recuperando saberes y "creencias de base" provenientes de la vasta historia formativa de una disciplina (que la geografía la acredita) y de nociones transdisciplinarias esclarecedoras.

Cerrando esta Introducción, cabe aclarar que en la exposición de las ideas de este ensayo se van articulando momentos de análisis sobre la impostación del nuevo nombre de los EGAL (muy ligado a las posturas ideológicas señaladas), desde una heurística en torno a las nociones teóricas asumidas -antes explicitadas-, combinando así momentos del pensamiento crítico con otros de índole propositiva y argumentativa emanados de mi propio punto de vista, sostenido por argumentos provenientes del enfoque desde el cual se interpela al objeto de indagación. De este modo, el desarrollo siguiente adopta la forma de un bucle dialéctico que conjuga la exploración semiótica en torno a un nombre y la búsqueda de superación de las limitaciones discursivas que se van identificando; instancia ésta que se alcanza con la aproximación al sentido subyacente en el develamiento de las intencionalidades operantes. Para esto se recurre a una actitud hermenéutica, no al estilo de Habermas para quien la reflexión debe ir 
seguida de transformación, o sea, de práctica política, sino más bien al estilo de Gadamer para quien toda comprensión de algo implica una pre-comprensión que asuma los prejuicios entrañados a la existencia humana misma (en las situaciones de vida) e implícitas en todo punto de vista. Por otro lado, nos aproximamos también a Ricœur, en una posición intermedia, quien propicia un diálogo entre la hermenéutica (como forma de pensamiento dirigida a la comprensión) y la crítica ideológica (de la línea de Habermas). Sin embargo, para que tal diálogo se dé, ninguna de las posturas en disidencia pragmático-discursiva deben considerarse autorreferenciales, sino dispuestas a examinar su propia historia formativa y sus efectos, y asumir "qué" de dicha historia puede ser arrojado a un espacio de debate auténtico "inter" o "trans" comunicacional.

Cabe remarcar que el propósito de este ensayo -como se dijo más arriba- no está en confrontar posturas ideológicas, sino en "poner de manifestó" ciertos aspectos (de índole ontológica, cognitiva y semiótica) que están en el subsuelo del cambio de nombre del evento que nos ocupa. En consecuencia, debe quedar claro que aquí se analizan y discuten estos aspectos desde autores que, acorde al enfoque asumido, aportan categorías generales para fundamentar las ideas tratadas; en ningún momento se debate con otras concepciones (ideológicas) vii que subyacen en las intencionalidades de quienes protagonizan el cambio de nombre, ni se busca contraponer argumentos que no exponen, porque el nombre ya ha sido cambiado "de hecho" sin un análisis profundo, plural y multifacético que contemple todas las posturas frente al tema. En contraposición, ya en la 1ra. Circular del próximo EGAL a realizarse en Córdoba (Argentina) en 2021, el cual acogió la propuesta de nombre que fuera "anunciada" en el EGAL anterior (en Quito, Ecuador, 2019), se decía: "este planteo fue discutido, debatido y acordado entre representantes de la Red de Geografía de Universidades Públicas Argentinas y la Comisión Organizadora de Córdoba, celebrada en diciembre de 2019". No obstante, sabemos que no fue tan así, pues cuando mis colegas del Departamento de Geografía de la UNNE participaron en la mencionada reunión, habiendo llevado la "propuesta alternativa" (tratada en la sección final de este ensayo), la Comisión Organizadora del próximo EGAL respondió que esa decisión ya estaba tomada y que no tenía nada que ver con los fundamentos epistemológicos de la geografía, sino que era una "decisión política". Podemos notar aquí, desde el vamos, una contradicción entre la enunciación (las palabras huelgan en el discurso) y la acción misma.

\section{Desarrollo: Argumentación de las ideas centrales}

\section{Antecedentes de la reflexión y discusión: el punto de partida}

El contenido de este ensayo, que busca explorar ideas sobre los asuntos antes anunciados, pivotea en torno a una cuestión de fondoviii que abreva en la famosa frase "el mapa no es el territorio", gustosamente repetida por Gregory Bateson (1993), uno de los precursores de las ciencias cognitivas y del pensamiento transdisciplinario; expresión que Bateson adoptó del filósofo Alfred Korzybski (1994)ix haciéndola suya para clarificar numerosos deslizamientos (yerros mentales) en que suele incurrir el pensamiento humano cuando pretende referirse a "algo". Detrás de esa expresión hay un asunto basal: la realidad y la representación mental de esa realidad, es decir, entre "algo" (la cosa) y lo que sobre ese algo construimos (un "objeto", un mapa mental, una significación... o "semiosis" al fin). Sólo por la transposición de sentido que crea y provoca la semiosis, esto es, la intervención de la subjetividad que busca su "aprehensión" y "comprensión", ese "algo" (la cosa) se vuelve un "algo inteligible", es decir, un "objeto" cognoscitivo. En ese construir interviene tanto el pensamiento (sobre ese algo) -operante a partir de cierta estructura mental- como el lenguaje con que nos 
referimos a él y, además, nuestra propia experiencia existencial desde donde modelizamos y damos sentido al mundo, proceso inherente a toda ciencia (incluida la geografía). Un criterio que sintetiza y expresa que algo es "producido" -desde este enfoque- y no es simplemente un algo "dado", amorfo o la cosa en sí -en términos de Kant (2007)- es, por cierto, encarar el problema como una "construcción semiótica". En consecuencia, la motivación de fondo de este ensayo de discusión terminológica es la búsqueda de aprehensión del "sentido", mediante un abordaje centrado en el "objeto mismo de la reflexión" -siguiendo a Hegel (2002)- y no en una crítica superficial hacia otra/s postura/s antagónicas, pues esto último sería incurrir en una "crítica externa" que no es constructiva ni superadora. De ahí que este ensayo preserva, en su desarrollo, el anclaje en disciplinas generales (o transdisciplinas) que permiten inteligir un asunto que tiene componentes cognitivos, ontológicos, semióticos y epistémicos.

Pero situémonos ahora en el punto de partida de la reflexión: el referido evento en el campo geográfico, cuyo nombre analizamos.

Los "Encuentros de Geógrafos de América Latina" (o EGAL, como se lo conoce) constituyen el evento científico en el campo geográfico más importante de nuestro continente que, desde hace más de treinta años, viene realizándose para aportar e intercambiar ideas y conocimientos en torno a temas-problemas relevantes de las realidades geográficas de nuestros países latinoamericanos.

Ante la inquietud de un grupo de cultores (y/o simpatizantes) de la geografía (más precisamente, geógrafas) que, en el último Encuentro realizado en Quito, Ecuador (2019), propusiera cambiar la denominación de este evento, expreso y fundamento a continuación mi punto de vista (debatido en su momento en la comunidad de cultores de la geografía a la que pertenezco: el Departamento de Geografía de la Universidad Nacional del Nordeste (UNNE), Argentina). Las razones que autorizan a recoger en lo propio un posicionamiento colectivo (las conclusiones de tal debate) fueron anticipadas más atrás, aunque es preciso subrayar que el contenido de este ensayo proviene de mi propia formación y trayectoria, sobre todo en el posgrado. Mis recorridos académicos me hacen acreedora de un pensamiento autónomo, forjado en ideas cultivadas en los campos de análisis en los que vengo trabajando de mucho tiempo atrás.

Debe quedar claro, desde el comienzo, que aquí no se cuestiona, ni se pone en tela de juicio, la legitimidad del pedido de cambio de denominación del referido evento, proceso que, por otra parte, viene gestándose, aproximadamente desde el EGAL 2009 (en Montevideo, Uruguay), para dar visibilidad a las mujeres geógrafas y reivindicar su rol como científicas. En orden a los estudios de género y la espacialidad, los trabajos antecedentes marcan la escasa presencia de estos contenidos en los eventos científicos en geografía y en las revistas geográficas. Mónica Colombara (2018) señala: "Con relación a los Encuentros de Geógrafos de América Latina: continúa escasa la representación de trabajos con perspectiva de género y/o con uso de la categoría de género (...)" (pp. 16-17). Y tomando el desarrollo de los EGAL en el período 2013-2017 especifica que los trabajos en género representaron el 1,8\% del total de trabajos comunicados. ${ }^{x}$

Precisamente ante esta necesidad -sentida entre los participantes de estos Encuentros- en un principio se había propuesto la iniciativa de cambiar la denominación fundante de los EGAL por la de "Encuentro de Geógrafos y Geógrafas de América Latina", la que no tuvo eco y, por ello, se arribó a la reciente propuesta hecha en el último EGAL (celebrado en Ecuador, en 2019). 
En efecto, en dicho Encuentro se había sugerido, como nuevo nombre, el siguiente título: "Encuentro de Geografías de América Latina". Por ello, en lo que sigue me ocuparé de esta última denominación anticipada en el contexto del EGAL de Quito (Ecuador) 2019 y ligada a posturas feministas a ultranza (y otros grupos activistas) en cuyas enunciaciones al respecto hay un conjunto de "sentencias" despreciativas y hasta condenatorias de los cánones habituales de la ciencia, rechazando y desacreditando toda práctica científica que "no encaja" en sus criterios y presupuestos que intentan justificar. ${ }^{\text {xi }}$ Así pues, el "Pronunciamiento de las geografías críticas y autónomas" (2019), presentado en el marco del EGAL de Ecuador (2019) comienza diciendo: "El encuentro fue un éxito de compartires y conspirares" (p.1), planteando luego una larga lista de denuncias; se habla de una geografía teórica y aplicada de corte neoliberal; la geografía que justifica y refuerza el avance del fascismo, la xenofobia, el colonialismo, el nacionalismo metodológico, el extractivismo académico y que impulsa el canibalismo intelectual. Proponen entonces: una geografía feminista, anticapitalista, auto-crítica, etc.

Teniendo en cuenta este contexto, permeado por la propuesta presentada en Quito por un grupo, desarrollo a continuación las ideas que fundamentan este ensayo, encarado desde otro ángulo. Para una mejor individuación de los argumentos aportados, éstos se organizan en ítems para su tratamiento lógico.

\section{Hacia los orígenes del evento}

La denominación tradicional de estos Encuentros -como se han llamado hasta ahora- constituye un símbolo que le otorga identidad, singularizando y distinguiendo el quehacer geográfico latinoamericano en la socialización de saberes en este campo (geografía) a nivel mundial. Es decir, el evento tiene "historia formativa" y un "sello distintivo propio" a escala internacional, con una reconocida tradición. Por ello, una propuesta de cambio de nombre debe preservar el sentido originario, su "razón de ser" fundante.

El motivo central de los EGAL radica en compartir e intercambiar saberes sobre la "ciencia" geográfica entre quienes la cultivan en Latinoamérica. De ahí que la denominación originaria comienza con la palabra "Encuentros...". Si bien en éstos la participación femenina estuvo presente, es dable pensar que uno de los propósitos del cambio de nombre sea lograr mayor visibilidad de sus trabajos, de temas de género y de nuevos actores protagónicos en el "hacer ciencia geográfica". Pero de ahí a buscar desacreditar o negar el vasto edificio cognoscitivo geográfico endilgándolo de opresor, colonizador, excluyente, etc., constituye, como mínimo, un "exceso de pretensión".

Coincidimos en que hay que abrir la geografía, pero esta apertura no puede darse negando una parte de la historia para reivindicar otra. Es preciso asumirla como un "sistema complejo".

\section{Necesidad de preservar la esencia de los Encuentros}

Sin desconocer ni dejar de lado la diversidad de producciones, problemáticas espaciales (geográficas) de nuestros países, y la variada procedencia y participación de hombres y mujeres de nuestro continente que cultivan la geografía, es evidente que la denominación propuesta en Quito desplaza el espíritu convocante de estos Encuentros, que -como sabemos- atañe al "hacer" ciencia, es decir, es inherente a las miradas, aportes y ejes de debate, cuestiones vinculadas a la "práctica investigativa" de geógrafos y geógrafas. Es decir, el acento de los Encuentros ha girado, desde sus inicios, en la praxis científica y en las contribuciones de conocimientos que, desde los 
procesos investigativos, reflexivos y críticos, han hecho (y hacen) hombres y mujeres de nuestro continente a la ciencia geográfica. Sin embargo, en la difusión del próximo EGAL a realizarse en Córdoba (Argentina) en 2021, se afirma que el foco estará "en los saberes y quehaceres geográficos, y no sólo en los sujetos que los producen"xii $\left(1^{\circ}\right.$ Circular, EGAL 2021, p. 1). Este deslizamiento en pos de reivindicar cierto "tipo de práctica geográfica" (ligada al activismo social y político), en el pretendido afán de aglutinar bajo ese paraguas el saber geográfico, confunde y se aleja del sentido fundante de los EGAL. Pero compárese esto con lo afirmado en las Memorias del $\mathrm{X}$ EGAL celebrado en San Pablo (Brasil) en 2005:xiii

El espíritu esencial del décimo EGAL, señalado en el programa, es el de conservar la idea original, para promover el debate e intercambio de la producción geográfica contemporánea, profundizando sobre la reflexión de los problemas y las preguntas que la época contemporánea nos impone (Carretero Bernal, 2005, p. 150; la negrita es mía)

\section{Riesgo de desvirtuación de la ciencia geográfica}

Nótese entonces que el énfasis de los Encuentros recae en los sujetos hacedores de la "ciencia geográfica", quienes, reunidos periódicamente, aportan ideas, datos empíricos, analizan y discuten sobre fundamentos epistemológicos y estrategias metodológicas, y sobre los hechos estudiados, las realidades geográficas (en sus más variadas temáticas) y las teorías asumidas que permiten explicarlas y/o comprenderlas. Desde este punto de vista, cambiar su denominación de "Encuentro de Geógrafos..." por "Encuentro de Geografías de América Latina" produce, en primer lugar, una significación que alude a una diversidad de ciencias geográficas (como si hubiese muchas "geografías"), cuestión que no podemos sostener si se consideran los mismos criterios con que se evalúa el estatus de otras ciencias; así, por ejemplo, se habla de la física (y no de las físicas), de la biología (y no de las biologías), de la antropología (y no de las antropologías ${ }^{\mathrm{xiv}}$, entre otras. En este sentido, tanto el documento nombrado supra ("Pronunciamiento...", presentado en Quito) como en la difusión del próximo EGAL (2021) aparecen expresiones como éstas: "El contexto de avance neoliberal interpela a nuestras Geografías [con G] y las desafía a promover aportes críticos que tiendan a la equidad e inclusión social..."; se habla de "geografías latinoamericanas"; sin contar que casi todos los ejes temáticos aluden a una pluralidad de "ciencias geográficas" (por ej. "Las geografías en/desde América Latina..."; "Geografía(s) para la(s) diversidad(es)..."; o "Geografías feministas, del género y de las disidencias sexuales", entre otras expresiones. Insisto: los nombres no son ingenuos, ni vacíos de contenido. La significación atraviesa tanto el aspecto "sintáctico" de las construcciones discursivas como el proceso comunicacional y sus efectos.

Como sabemos, una ciencia es un corpus coherente, sistemático y lógicamente consistente de saberes, teorías, supuestos epistemológicos, categorías conceptuales, métodos, técnicas, valores vigentes en la comunidad de sus hacedores, entre otros aspectos. ${ }^{x v} \mathrm{Si}$ bien al interior de cada ciencia existen sub-dominios o partes de una disciplina que adquieren un cariz propio, por distintas razones (cuando se habla -por ejemplo- de física cuántica, biología molecular, etc.), estas denominaciones corresponden a desarrollos científicos específicos sobre una parcela bien definida de una ciencia, o a especializaciones. Pero tengamos en cuenta que, en razón de la naturaleza (o esencia) de su objeto de estudio, la geografía no admite fragmentaciones, ni especializaciones, tal como lo ha señalado Rey Balmaceda (1974-75), 
caracterizándose por constituir -a su criterio- una forma de pensamiento que integra las relaciones existentes en un lugar, región o territorio determinado. Por otra parte, cuando se habla de geografía cultural, geografía del comportamiento, geografía ambiental, etc., se está haciendo referencia a distintos "enfoques" (o miradas) según las temáticas y los métodos de indagación que se priorizan en función de las demandas que plantea "el estudio de" ciertos hechos asumidos como objeto-problema). Es decir, estos puntos de vista (enfoques) hallan su razón de ser en las necesidades cognitivas que emanan del objeto de estudio, según la vía de entrada asumida sobre cierto fragmento de la trama del espacio, esto es, de la inextricable red de relaciones espaciales que se construye (o forja) en una parcela (mayor o menor) de la superficie terrestre.

En consecuencia, no se puede separar el objeto de estudio de la "pretensión (y acción) cognoscitiva" que sobre él (y en cooperación con éste) establece un sujeto pensante. De ahí que el objeto tampoco es la realidad misma, sino una construcción a partir de cierta modelización previa de ese "algo" (un espacio, una trama de relaciones geografizadas, una tupida red de interacciones entre la naturaleza y la sociedad) que se pretende estudiar. Sin embargo, aun cuando las vías de penetración e interrogación al espacio varían, según los objetivos fijados por quien estudia ciertos contenidos geográficos en la faz de la Tierra, el objeto de estudio es el "espacio geográfico", en torno al cual existe hoy día un consenso indiscutido. Bien es sabido que la construcción de un objeto de conocimiento también es un devenir, el resultado de una historia formativa, de su propia evolución como objeto cognoscible. .vi $\mathrm{Y}$ aunque esta búsqueda de precisión de un objeto es concomitante a toda ciencia, aquí se trata del mismo campo -la geografía-, aun cuando varíen sus métodos de investigación, sus puntos de vista y las tecnologías que coadyuvan a tal intelección.

Por lo dicho, cabe subrayar que la geografía, como ciencia, es "una", y ocupa un estatus propio diferenciado en el contexto científico, en el campo de las ciencias que estudian al ser humano en sociedad, en sus múltiples facetas y realizaciones (hoy aglutinadas bajo la expresión "ciencias sociales"). Empero, la geografía que, en tanto ciencia, "aterriza" su trabajo investigativo en la relación "sociedad-naturaleza" (esto es, el "espacio geográfico") anclada en la "superficie terrestre" -que es su "dominio" de estudio-, alberga, en su riqueza y complejidad intrínseca, diferentes enfoques xvii, métodos $^{\text {xviii }}$, técnicas diversas... que coadyuvan al conocimiento de su objeto formal específico (el espacio geográfico). Si bien las vías de indagación y de acceso a este objeto cognoscitivo son plurales, éstas siempre están "anudadas" al sello distintivo de la geografía como ciencia y a su identidad en el vasto contexto de las ciencias sociales y de la ciencia en general. ${ }^{\text {xix }}$ Es evidente que, siendo la geografía una ciencia social y humanística por vocación, "debe admitirse que los geógrafos orientarán sus reflexiones en diferentes direcciones influenciados por los intereses de sus países o por su clase social o por su formación ideológica" (Rojas Salazar, 2005, p. 156). La presencia de cierta ideología en todo conocimiento científico es inevitable, máxime en las ciencias sociales y humanas. Ahora bien, reducir la pluralidad de concepciones subyacentes en las investigaciones a una ideología que propugna imponerse (tolerando cierta indiferencia a otras) constituye una subversión del espíritu científico, al desvirtuar la aproximación al conocimiento verdadero desde distintos puntos de vista y perspectivas teóricas. Si bien se habla de la necesidad de generar diálogos y debates entre las "diferentes geografías", en el fondo hay un énfasis en ciertas formas de práctica geográfica que buscan reivindicarse. 


\section{De la sociabilidad del conocimiento geográfico a las realidades fácticas mismas: un error de incomprensión lógica}

Además de lo señalado, el cambio de nombre antedicho genera un viraje hacia los "hechos empíricos" en lugar de priorizar un "encuentro de sujetos" que aportan, discuten, debaten, etc., lo cual ha sido, por cierto, el fin de los EGAL. Este giro tampoco representa un cambio que re-centre la mirada en el "objeto de estudio" de nuestra ciencia, sino más bien hacia la misma "realidad geográfica material" que sirve de sustento fáctico a su conocimiento. En los mismos documentos (Circulares) que difunden el próximo EGAL, se habla en varios pasajes de "la(s) geografía(s)" connotando las problemáticas geográficas que son tema de estudio, mientras que, por otro lado, aparecen expresiones deslizadas a la unidad de la Geografía (en singular y mayúscula); por ej. al referir a: la tradición visual de la Geografía; la Geografía Física; la pedagogía y didáctica de la Geografía... La confusión está presente.

Este desplazamiento del eje del Encuentro desde los sujetos que hacen geografía a las realidades geográficas que son estudiadas por algún método de investigación constituye un yerro epistemológico de significativa importancia; éste consiste en confundir los hechos empíricos con el "objeto de estudio" de una ciencia, pues, este último, supone siempre -e inevitablemente- una definición epistemológica y, con ello, la adopción de determinadas categorías desde las cuales se "modeliza" (y "construye") dicho objeto (como objeto de conocimiento de una ciencia) y, en función de éste, se buscan respuestas a las preguntas que sobre los "hechos" se formulan. De ahí que Samaja (1995) -como ya anticipé- va más a fondo, sosteniendo que el objeto de toda investigación -en cualquier ciencia- resulta ser un "objeto-modelo", categoría que fundamenta en pensadores precursores como Husserl, Merleau-Ponty y Ladrière.

Reasumiendo esta concepción sobre la relación del sujeto investigador y ese "algo" (llámese situación-problema) que se busca develar (conocer) en el proceso investigativo, tal aproximación comprensiva que opera en los momentos iniciales en torno a la situación de investigación -avenida como "problema de estudio"- es una "construcción semiótica" (Lebus, 2017), dadas las operaciones que implican la intervención de signos (que articulan el pensamiento, la facticidad y la praxis misma del investigador) en la búsqueda de "aprehensión del sentido" que instala "eso" (un objeto presunto) que deseamos conocer. Esto es, en definitiva, un "proceso semiótico" que supone una actitud activa, reflexiva y constructiva del sujeto en íntima conexión con el objeto, a tal punto que resulta difícil, e imposible, discernir qué pertenece en esos momentos al hacer del sujeto y qué es inherente al objeto, porque, hemos de admitir, allí lo que hay es una construcción recíproca del sujeto y del objeto. ${ }^{\mathrm{xx}}$

En este sentido, cabe traer a colación el aporte de Husserl, quien entiende esta problemática relación no desde un enfoque general (como Kant -si bien considera la necesaria participación de intuiciones y conceptos en la cognición-) sino en términos de "cumplimiento" [cabe agregar, "efectivo"]. Para Husserl lo esencial no es la relación entre pensamiento y cosa, sino "las posibilidades en que se nos puede dar la cosa y, a su vez, las posibilidades en las que puede operar el pensamiento" (Isaza Restrepo, 2013, p. 220). El planteo de esta relación en términos de "posibilidades" entronca, a su vez, con el criterio "operatorio" de Ladrière (1978). Este "encuentro activo" -a modo de búsqueda intencional con que el sujeto se dirige al objeto- implica la intervención de la imaginación [recordemos que para Husserl (1962), la intencionalidad es "la peculiaridad de las vivencias de "ser conciencia de algo"." (p.199; la comilla y la cursiva son del autor)]. Por lo tanto, sostengo que la imaginación lejos de ser un extravío de la razón hacia la 
fantasía per se es, por el contrario, la vía más fecunda de intelección de "algo" (la cosa) asumida como objeto cognoscitivo; idea que resulta coherente con el pensamiento de Paul Ricœur. Así, mediante actos imaginativos podemos tener acceso al mundo, a la unidad de la cosa expresada en los fragmentos que de ésta percibimos en la acción de escorzar la realidad. Por ello, considerando que el acento husserliano no está puesto en la relación directa entre pensamiento y cosa, sino en la "imagen" de ésta con que accedemos al conocimiento, vía la percepción entendida como "vivencia" que se presenta a la conciencia, Isaza Restrepo (2013) afirma que el planteo de Husserl representa una superación de la concepción clásica de la relación sujeto-objeto; aserción que va en la línea del pensamiento de Merleau Ponty.

La posibilidad de "atrapar" al objeto (en su unicidad) desde las misceláneas con que, a través de la imaginación, accedemos a él, a partir de fragmentos "significativos", reivindica el importante papel de los actos creativos en la génesis del conocimiento; mediante la imaginación o -diríamos, en anuencia con Peirce (1970)- por saltos "abductivos" podemos ir del fragmento (la parte) a la totalidad. Esto implica la imaginación creadora pues conlleva "la suposición de que existe una parte del objeto que no se encuentra en la faceta que estamos observando de este, la cual terminamos por tener en cuenta sin reclamar constatación alguna" (2013, p. 222) -aseveración en sintonía con la filosofía de Ricœur sobre la "imaginación productiva" "xxi-, lo que, a mi criterio, destaca el rol del sujeto "dirigido a" la realidad externa, o sea, lo que el "sujeto" pone de sí en la "aprehensión" del "objeto".

Este proceso constructivo, activo, del sujeto lanzado al objeto es, en definitiva, una semiosis pues hace operante la generación de una significación (concreta) en dicho acto.

\section{Confusión del objeto cognoscitivo con los "hechos" geográficos}

Siguiendo esta misma línea de razonamiento, si adoptamos el punto de vista de Peirce (1987) sobre el signo, o sea, su naturaleza "triádica", es evidente que lo que pertenece al objeto (su facticidad) y lo que es del orden de la subjetividad constituyen una unidad inescindible, toda vez que la captación del sentido sobre "algo existente" es posible mediante el "interpretante" que, por un lado, es un componente de todo signo (por ser triádico) y, por otro, es asimismo un signo. Esta "articulación" o -como prefiere decir Parret (1993)- "presentificación" que genera todo signo mediante el papel del "interpretante" torna imposible separar objeto del sujeto. Al respecto, afirma Parret:

El intérprete como un signo propiamente dicho tanto como un ingrediente esencial de cualquier relación sígnica, no es la subjetividad personalizada que produce y comprende la significación-en-el-mundo, como lo es en hermenéutica. No es un actor personal, un agente real que "existe" autónomamente como una entidad ontológica: es el signo mismo. (p. 57; el destacado en cursiva y entre comillas son del autor)

En consecuencia, en la medida en que el intérprete (más precisamente, el interpretante -peirceano-) suscita (o provoca) la semiosis tornándola una acción (la acción semiótica o la lógica del signo), podemos afirmar que la construcción del objeto de toda ciencia, así como la identificación, delimitación y modelización del objeto de cualquier investigación (incluida la investigación geográfica cualquiera sea el tema de estudio) instala una semiosis. El objeto así delimitado es el producto y, a la vez, el proceso generativo de dicha semiosis y no la realidad fáctica en sí, la que, en el proceso 
semiótico interviene como el referente y, por lo tanto, conlleva el "presupuesto del mundo" (o en términos husserlianos, el "horizonte del mundo"), es decir, de un cierto algo pre-existente que suscita la semiosis, pero que no la atrapa por sí mismo.

En consecuencia, la identificación y primeras aproximaciones a la situaciónproblema (lo que comúnmente llamamos "realidad geográfica") que busca ser delimitada (en sus entes y propiedades de análisis) a fin de ser develada (conocida) en el proceso investigativo y que, por tal motivo, conlleva un esfuerzo de "aprehensión" como objeto [y acto] cognoscitivo, es un proceso semiótico que, por su esencia, no admite la separación del sujeto respecto al objeto, y viceversa. O dicho, en otros términos, "aunque el investigador se figure que su teoría describe la realidad misma, lo cierto es que describe un modelo de la realidad" (Samaja, 1995, p. 137). Este modelo se cimienta en las vivencias del sujeto, ancladas en sus experiencias de praxis o -en términos de Husserl- en el horizonte del mundo que es construido mediante un yo en el flujo de vivencias compartidas con otros yo(s). $Y$ esto es otra manera de decir que nuestro acceso a la "realidad bruta" es desde la construcción de significaciones.

\section{Soterramiento del objeto y libre albedrío de los sujetos en la ciencia geográfica: de la pragmática del signo a la pragmática perversa}

Posicionados en esta concepción del "conocer" que vengo tratando -en tanto proceso (que integra sujeto y objeto)- hallamos argumentos potentes para discutir los efectos epistémicos que provoca la denominación propuesta en el último EGAL celebrado en Quito (Ecuador) en 2019. En el nuevo nombre ya adoptado para el EGAL 2021 (Encuentro de Geografías de América Latina), puede notarse cómo se desplaza el eje del evento hacia el lado de la empiricidad, con el riesgo no sólo de mutilar la unidad del "objeto / sujeto" en su dinámica constructiva y dialéctica, sino -peor aún- de provocar un deslizamiento hacia posturas filosóficas que hoy se consideran superadas -por sus limitaciones- tal como el "empirismo ingenuo" -así acuñado por Alan Chalmers (1988)-, o bien el "realismo", igualmente caduco en el pensamiento científico actual, pues la "creencia" en la trascendencia de la cosa (su existencia independiente) resulta ser una vacua ilusión, porque, como señala Husserl, [la cosa] "jamás es un objeto existente en si" (1962, p. 109), a lo que agrega, "un objeto tal que no le afecte para nada la conciencia y su yo" (p.109).

En consecuencia, detrás de los "camuflajes" de sentido -escondidos en la nueva denominación propuesta para los eventos EGAL, que vengo analizando- se oculta, asimismo, la "creencia" de que la ciencia es analogable a "disímiles posturas" (o posicionamientos ideológicos particulares) sin considerar, en el fondo del sustrato cognoscitivo, lo que el "objeto" pone de sí. Es decir, que aun cuando evidentemente los "discursos" parecieran entronizar el papel protagónico del sujeto sin más, por "defecto" de esta manera de pensar -reduciendo el conocimiento a posturas "subjetivas"- se omite, se oculta o se borra totalmente lo que el mundo en su plenitud (entendido como experiencia humana compartida remitida a lo factual) "alberga" (más allá de las disímiles miradas y creencias con que buscamos aprehenderla). Este "ser" (o dimensión ontológica) es en última instancia lo que la ciencia busca captar, comprender y/o explicar. Samaja (1995) señala que el conocimiento científico supone tanto la regularidad de los objetos como la regularidad de los sujetos; esto último es, sin duda, la "intersubjetividad", la cual es muy distinta a las meras posturas subjetivas.

Un antecedente de esta idea lo hallamos en la fenomenología de Husserl, en la que el presupuesto de correlación entre "sujeto" y "mundo" es el fundamento de todo 
conocimiento posible. Esta existencia relacional anclada en el "mundo de la vida", en el "horizonte de las vivencias humanas", es anterior a toda posibilidad de cognición (como lo era para Kant el esquema transcendental), pero a diferencia de éste, Husserl asienta el conocer en experiencias singulares suscitadas en la vida misma (no en un esquema universal preexistente). Este presupuesto y "plataforma del conocer" (y de la existencia humana) se revela como un nudo problemático, que la epistemología clásica heredera de la disyunción entre "mente" y "mundo" -proveniente de Descartes- no comprendió ni supo explicar. El propio Husserl expresa este Nudo Gordiano del conocimiento en estos términos "La paradoja de la subjetividad humana que es sujeto del mundo y conjuntamente objeto en el mundo" (1984, citado en Herrera Restrepo, 2010, p. 250).

Empero, los medios de difusión -en curso- del próximo EGAL (2021) expresan una constante puja entre las "ideologías" operantes, descuidando, a mi criterio, la impronta que el objeto pone de sí en todo proceso cognoscitivo y, a la par, la regularidad de los sujetos (de la que habla Samaja). A modo de ejemplos, nótese este desliz en los siguientes extractos de la Circular $\mathrm{N}^{\circ} 1$ : (refiriéndose al eje temático de las geografías feministas, del género y las disidencias sexuales, dice: "eje se plantea entonces como una provocación a tensionar las barreras epistémicas y metodológicas" (p.7); o bien, sobre el eje 'Ecología política, naturaleza(s) y territorio': se busca "promover los debates que se enfoquen en la construcción de contra-espacios o espacios otros" (pp. 8-9); y en el eje referido al espacio urbano se afirma: "se promueve el envío de propuestas que tensionen las fronteras entre el mundo de la investigación y de la práctica social" (p.10). Nótese el alcance que asumen las palabras: "provocación", "tensión", "contra-espacios". Sin duda, se resalta la dimensión del polo comunicacional (y, por ende, subjetivo) del proceso semiótico, generando así lo que Parret (1993) llama una "pragmática perversa".

En concreto, en ese giro terminológico propuesto "Encuentros de Geografías de...", si bien "pareciese ser" que el énfasis recae sobre las realidades geográficas mismas -que la geografía (como ciencia) pretende estudiarlas-, tal desliz oculta la verdadera intencionalidad: instalar "puntos de vista" particulares, sean personales, grupales, comunitarios, tal como opera en otros ámbitos de la vida social y política, pero sin considerar los modos de conocer científicos, esto es, la búsqueda de esa articulación (vía la contrastación y resolución dialéctica, trabajosa, y plena de signos y significados) que supone la relación "contradictoria" del objeto y del sujeto en el proceso de conocimiento [geográfico]; cuestión presente como construcción semiótica, dada la aprehensión del "sentido" que representa (y opera en) la respuesta a cierto problema de estudio y que atañe no sólo al proceso de la ciencia en general (de la geografía, en este caso) sino que se replica en cada investigación singular, precisamente por ser intrínseca al "modo de proceder" de la ciencia.

En este sentido, la cita precedente de Parret (cfr. supra) nos advierte que no hay que confundir el proceso semiótico que se instala como movimiento cognoscitivo operante en toda investigación -suscitado por la "presentificación" que crea el signo mediante el interpretante (o intérprete, en un sentido menos específico)- con puntos de vista subjetivos. Cabe subrayar que este intérprete es intrínseco a toda semiosis y no es individualizable en un sujeto en particular; más bien, el interpretante constituye la "Regla" que posibilita la presentificación de un término en el otro en la relación sígnica.

Al respecto, Parret es contundente al decir que "la presentificación es interna a la semiosis" (p. 58). En razón de ello, la denominación propuesta en Quito 2019 para el evento que venimos tratando, esto es, "Encuentro de Geografías de...", oculta el giro, subrepticio, que reduce el objeto de estudio a la mera empiricidad (los hechos 
geográficos mismos) a la vez que esconde el peligro de "subvertir" esa realidad por la entronización de cualquier punto de vista asumido como igualmente válido para cierto problema investigado, confundiéndose así el "interpretante" (intrínseco a toda semiosis) -la que tiene lugar en el proceso investigativo- con posturas "personales", es decir, "marcos interpretativos" subjetivos donde el conocimiento se mimetiza con el lugar del intérprete (de un sujeto concreto -aun cuando éste sea un grupo-) en vez de entender al develamiento cognoscitivo operante en la investigación como un esfuerzo de aprehensión semiótica articulada por cierto interpretante (Regla) que lleva al descubrimiento del sentido del objeto-problema que se estudia. Esto último es intrínseco a toda semiosis y no la reducción a un punto de vista particular que, como tal, es sesgado.

\section{Desnudando la semiosis oculta en el nombre propuesto en Quito, 2019}

Por lo dicho, el deslizamiento terminológico anticipado en el Encuentro de Quito 2019, no es neutro e implica no sólo una concepción epistémica mutilada, sino también desvirtuada de lo que identifica a la ciencia y, a la vez, establece su diferencia con otras formas de conocimiento y de praxis sociales.

Retomando nuevamente la Circular del próximo EGAL, se puede advertir un intento de poner la ciencia "en el mismo plano" de las restantes praxis sociales (incluso desde una mirada muy direccionada a "ciertos temas" y una tenaz pretensión de revisar toda la ciencia, toda su historia formativa, por considerarla colonizadora y opresora, aliada de los poderes hegemónicos...). Puede apreciarse claramente esta intencionalidad en la siguiente cita, extractada de la $1^{\circ}$ Circular del EGAL (2021) cuando se presenta el eje de reflexión epistemológica sobre "las geografías en América Latina":

Se busca un análisis crítico tanto de las connivencias entre las prácticas de la tradición disciplinar y las políticas estado -colonialneocoloniales capitalista, como las convivencias entre academia y colectivos subalternizados, en donde se disipan las fronteras entre el mundo de la investigación y de la práctica social, y se resignifica el conocimiento disciplinar desde la interdisciplinariedad y el diálogo de saberes. (p. 6)

Este "poner la ciencia" en pie de igualdad con las restantes prácticas sociales plantea numerosos problemas. Por ejemplo, no resuelve los viejos dilemas de la reflexión epistemológica, como ser: la relación entre lo que es propio de una ciencia (su "ser específico") y lo que pertenece al "contexto" (historia externa, marcos socioculturales, etc.); tampoco explica las vías de ingreso de los componentes creativos al proceso de la ciencia y, mucho menos, cómo se legitiman los criterios de validación del conocimiento producido. Aunque la máxima del "todo vale" postulada por Feyerabend (1981) es al respecto un gran "atractivo", cabe advertir al lector que éste pensó su obra con un espíritu crítico, reaccionario, a la visión ortodoxa de la ciencia reinante a mediados del siglo XX (neopositivista), pero sin haber propuesto una epistemología alternativa.

Por otra parte, la "disipación" de la especificidad de la ciencia, con el ánimo de "instalar" ciertas ideologías constituye, en sí, un proceso colonizador del pensamiento que coopta la libertad reflexiva, base del impulso que toda práctica científica auténtica exige para poder "comprender" las nuevas realidades fácticas que está llamada a estudiar. 
Volviendo al eje del ensayo, si tal deslizamiento igualmente se produjese, es decir, si se llegase a adoptar la denominación allí propuesta (que -como se dijo- jya se ha producido!), se correría el riesgo de que "cualquier argumentación" podría tener la pretensión de ser científica, tendiéndose así "peligrosamente" a convertirla en ideología social, política o de activismo partidista (en el más amplio sentido del término). Aun cuando la ciencia "recapitula" en su propia dinámica otras formas del saber humano (creencias tenaces, debidas a la autoridad, etc.), la lógica de su desarrollo opera o está compulsada -por su propia esencia- a la comprensión y/o explicación de los hechos estudiados desde ciertas categorías conceptuales que proporcionan las nociones inteligibles para develar el sentido de "eso que está ahí" (asumido como "hechos") en la realidad (fáctica), considerado como objeto de indagación. Este proceso es lo que Samaja (1995) denomina "cartografiado" entre conceptos y hechos (o datos referidos a cierto estado empírico) que se materializa, en la investigación concreta, a través del diseño, análisis e interpretación de "matrices de datos" relacionadas entre sí y entramadas en una totalidad compleja que, precisamente, pone en interacción (y en unidad inescindible) al objeto cognoscible y al sujeto cognoscente.

\subsection{El punto crítico: reduccionismo del conocimiento geográfico}

De ahí que al sustituir la denominación habitual de los EGAL por la expresión "Encuentro de Geografías de América Latina" se está generando un deslizamiento hacia el lado de la empiricidad de los hechos de los que la geografía (como ciencia) se ocupa, provocándose -sin querer- una reducción del conocimiento geográfico.xxii En este desplazamiento del sentido no hay siquiera una focalización en su objeto de estudio, el espacio geográfico, sino un "descenso" hacia el "material empírico" con el que trabaja el estudioso para arribar al conocimiento del espacio geográfico.xxiii

Este último giro constituye un reduccionismo del espacio, así como de la mirada que el geógrafo o la geógrafa proyecta sobre él, desvirtuándose pues el conocimiento que es integral y no se limita a los "hechos" considerados. Y, si tal fuese el caso, hipotéticamente hablando, sería mera descripción de un estado de cosas desde el sentido común y no "ciencia" como asumimos que "es" la geografía.

Por otra parte, no se puede pensar un "Encuentro..." que no sea, precisamente, un "encuentro entre" sujetos, con distintas voces, miradas e indagaciones en torno a un problema investigativo que se busca dilucidar, comprender y/o explicar. Este proceso de "alumbramiento" cognoscitivo transcurre en el plano de la "intersubjetividad" (la que no se confunde jamás con puntos de vista "subjetivos"). Pero para buscar la verdad en una trama de interacciones múltiples no se puede "negar" (ni desconocer) la historia de un campo científico (de la geografía) lograda en su ardua génesis (como lo es, en realidad, todo proceso humano) y cuya "estructura resultante" aflora como un corpus consistente de teorías, métodos, categorías analíticas, etc.

Por lo expresado, resulta evidente que el cambio propuesto ofusca asimismo el papel protagónico de quien construye ese conocimiento, con lo cual se desvirtúa indeseadamente- el espíritu fundante de estos Encuentros (EGAL) -ser un ámbito convocante de los hacedores de la ciencia geográfica- produciéndose así el efecto contrario de lo que se propicia, lo cual conlleva un empobrecimiento de la práctica investigativa, de la búsqueda de miradas superadoras, del desarrollo de las posturas crítico-reconstructivas de nuestra "ciencia" que, cabe remarcar, versa sobre el "conocimiento" del espacio (conocimiento en el que quedan implicados los "hechos 
geográficos" -o si se prefiere una expresión más imprecisa- las distintas "geografías de América Latina").

\section{Mi propuesta: ensayo de un nombre alternativo}

Ateniéndonos a las razones antes puntualizadas, sostengo que la denominación que fuera anticipada en el último EGAL llevado a cabo en Ecuador (2019) no es adecuada y, en su defecto, "propongo" -a los fines de ser discutida dónde y cuándo corresponda- la siguiente denominación para estos próximos eventos, a saber: "Encuentro de Profesionales de la Geografía de América Latina" (cuya sigla bien podría ser: EPGAL).

Al ser un Encuentro de "profesionales" de la geografía quedan incluidos tanto geógrafos como geógrafas y también personas de otras disciplinas científicas afines, que cultivan nuestra ciencia. Y, además, este nombre que sugiero, por una parte, preserva la esencia de estos Encuentros que desde sus orígenes priorizó el diálogo, la conversación fundamentada y el intercambio de ideas y conocimientos geográficos de los "sujetos-hacedores" de la geografía en contextos latinoamericanos y, por otra, compatibiliza con la necesidad social actual de no sesgar nuestra ciencia por cuestiones de género, incluyendo el trascendente papel que, desde tiempos muy lejanos, de manera consciente o sin proponérselo, han tenido en nuestra ciencia las "cultoras de la geografía" o -para decirlo de manera más franca- del "conocimiento geográfico". xxiv

[Si la denominación que propongo no pareciese acertada, o si se llegase a priorizar una postura más conservadora que busque mantener la sigla tradicional, cabe sugerir que, en última instancia, se opte por la expresión "Encuentro de Geografía de América Latina" (geografía sin la "s"), lo cual -insisto- sería incurrir en una contradicción -con las ideas tratadas hasta aquí- al recaer el énfasis más en la disciplina (como conocimiento sistemático, cristalizado o ya "formado") que en sus hacedores (y su hacer: como proceso). Y respecto a la sigla sugerida, cabe preguntarnos: ¿Qué es más importante? ¿Una sigla o la esencia (y el significado) que ésta (como "signo") evoca? Sin duda, una sigla no es más que la "representación" o, para ser más precisos, la "sintaxis representacional" de aquello que está siendo comunicado por dicho signo, esto es, el sentido genuino al que remite la semiosis que, por medio de ella -la sigla-, está abriéndose paso. Estas reuniones científicas periódicas de "geógrafos" y de "geógrafas" son, ante todo, "fenómenos comunicacionales" centrados en una ciencia: la geografía. ¿Renunciaremos a preservar ese espíritu convocante (y fundante de estos Encuentros) sólo por mantener intacta una sigla que, como todo signo, es un "vehículo comunicacional" que busca realizarse en la semiosis profunda que instala y a la cual remite? En suma, lo que cuenta es, en definitiva, el "sentido" del fenómeno comunicacional que la sigla suscita, y no meramente la "sintaxis" con la que ella, en tanto signo, se manifiesta]. ${ }^{\mathrm{x} v}$

En cambio, la denominación que introduje más arriba -"Encuentro de Profesionales de la Geografía de América Latina"- condice con las necesidades actuales de la ciencia (de la que no escapa la geografía) pues, hoy más que nunca, es preciso desarrollar el trabajo investigativo desde una perspectiva integral, que aúne la pluralidad de sus sujetos protagónicos. ${ }^{\text {xvi }}$

Estamos llamados a este gran desafío de generar una ciencia comprometida con la sociedad, donde el rol del "ser" geógrafo / geógrafa implique, en la producción misma de conocimientos, el rescate del "saber situado", anclado en los procesos 
culturales de cada lugar y, a la par, su involucramiento en problemáticas sociales complejas (como profesional pero también como agente social y ciudadano), a través de líneas propositivas de mejoramiento de la calidad de vida, el compromiso con el desarrollo sustentable, con políticas de gestión socio-territorial y la participación de actores locales en un proceso de co-construcción del conocimiento geográfico, recuperando las identidades de las poblaciones según su contexto y las circunstancias de vida en un espacio concreto. ${ }^{x x v i i}$

\section{Implicancias educativas de este tema}

El tema tratado en este ensayo entronca de lleno con la tarea educativa en la formación superior, universitaria y no universitaria. Un cambio de nombre de estos Encuentros, dada su relevancia científica en nuestro continente, no es un asunto banal. Todo cambio implica una epistemología asumida y hasta cierta concepción del mundo, al ser cantera primaria de nuestras representaciones y creencias más basales que asumimos sin cuestionarlas. Por eso la ciencia debe reflexionar sobre ellas, ejerciendo lo que Hegel (2002) llamó "crítica interna", centrada en el objeto mismo de la reflexión, y no en el mero ejercicio del criticismoxxviii superfluo, sin fundamento o impuesto a la fuerza. Hoy día, frente a temas actuales, tiende a instalarse el lado pragmático del signo (por ejemplo, un nombre, una corriente social, etc.) olvidando su significado profundo y el "sentido" de su ocurrencia. ${ }^{\text {xix }}$

En los últimos años se puede apreciar cómo se va gestando ese "peligroso deslizamiento" hacia una pragmática superficial bajo el ropaje de "actualidad". Llama la atención de que ya prácticamente no existen reuniones científicas en humanidades y ciencias sociales que no incorporen algún "Eje" atinente a "asuntos o cuestiones de género", temáticas descolonizadoras, emancipadoras, resistencias y luchas. Empero, es preciso recordar (y señalar) que la ciencia está llamada no sólo a desarrollar investigaciones per se, sino también a reflexionar ejercitando la fundamentación en conceptos, en teorías y en datos de la realidad.

Cabe preguntarnos así, en qué medida ciertas temáticas son asuntos "altamente trascendentes" que transcurren como parte misma de los procesos sociales, o hasta qué punto responden a concepciones, ideologías o slogans políticos que hasta suenan como discursos propagandísticos de determinados valores subyacentes, asumidos por un sector (y tal vez grupos minoritarios) que buscan legitimarse, mostrándose como la tendencia que "se viene", o la ideología que se propugna imponer. Cabe recordar -siguiendo a Benveniste (1999)- que la enunciación tiene un poder instituyente, a diferencia del lenguaje que en sí es abstracto. Como "posibilidad concreta" de la comunicación, la enunciación es contraria al dicho popular que afirma: ¡A las palabras se las lleva el viento! Por el contrario, en el pronunciar, en el decir, cobran entidad ciertos constructos y, por esta vía, se instituyen determinados modus operandi como creadores de realidad [en la misma línea de Austin (1962) sobre los "actos de habla" que, en virtud de ello, adquieren un carácter "performativo"].

Es por eso que la ciencia no es neutra. En consecuencia, buscar introducir determinados artificios so pretexto de ser "científicos" es despojar a la ciencia misma de esa crítica interna de la que hablé más arriba, desviando la tarea objetiva hacia fines no científicos, u ocultándola bajo el velo de una realidad que "se lleva puesto todo"; ergo, la ciencia no tiene más que ir tras ella, sin ningún atisbo reflexivo. Fue el ingenioso epistemólogo Ladrière (1978) quien advirtió el peligro que esto encierra; en mis palabras, ello implica el "descenso al precipicio" que conlleva una ciencia a la que se le 
ha cortado todo lazo con su fuerza emancipatoria, esto es, que ha sido vedada de su esfuerzo teórico genuino, al ponérsela en el mismo plano de la ideología o la actuación social o política, al juzgársela -desde tales posturas- como un saber vetusto ${ }^{\mathrm{xxx}}$, de ropajes anticuados, de empeños intelectuales banales que a nadie interesa. Sin embargo, toda ciencia es, en algún sentido, contra-hegemónica; dicho en forma simple: una ciencia nunca va por el lado de la correntada. Sin ese esfuerzo por descubrir nuevo conocimiento ningún logro científico hubiese sido posible.

Este último giro, a mi criterio, peligroso para el devenir mismo de la actividad científica (esto es, una geografía despojada de su reflexión teórica genuina) se esconde detrás de las pretensiones de imposición de ciertos discursos (ej. los de género, ciertos slogans anticapitalistas, anti (todo) -cabría decir- considerando un permanente malestar con este mundo "heredado" (de nuestra humanidad tal como ha devenido "hasta aquí"). No negamos que hay reivindicaciones justas y atendibles, pero otras constituyen ejercicios de poder (real o simbólico) que buscan imponerse al amparo de intereses políticos subyacentes; intereses que, a su vez, esconden otros trasfondos más sutiles y menos sostenibles éticamente.

Estas ideologías que, tiempo atrás, impregnaban lentamente el tejido social y pugnaban por introducirse en ciertos reductos -como los partidos políticos $u$ organizaciones sociales, entre otros-, hoy rebasan sus lugares originarios para imponerse en "todos los ámbitos" del desarrollo de nuestras sociedades, disputando los lugares del saber, penetrando solapadamente en distintos espacios institucionalizados de la educación. Desde tales discursos politizados y revestidos de poder -buscando penetrar en las conciencias-, esos lugares del saber son sumamente cuestionados por ser considerados machistas, sectarios, reduccionistas o anacrónicos, entre otros tantos adjetivos descalificadores.

Ahora bien, una propuesta que busca "subvertir" el orden existente no es más que la implantación de otro orden igualmente hegemónico y excluyente. En estos debates iniciales suscitados por la avidez con que se busca cambiar el nombre a los tradicionales EGAL, hay distintas posturas y una de éstas es, por cierto, una crítica auténtica que emerge, tímidamente, entre el eco de las voces que se levantan sobre este tema. Así pues, si hemos de bregar -como sostienen algunas voces- por una geografía "feminista", cabe preguntarnos: ¿Cuál es el cambio?, pues todos los "ismos" son igualmente perversos y limitantes, al ser "desviaciones" de la cosa (o sentido) originario. ¿Se sentirán los "geógrafos" (los cultores "masculinos") "contenidos" en una geografía "feminista"? ¿No es acaso la geografía -como ciencia, esto es, como saber institucionalizado, integrador, multifacético- mucho más que una "geografía" mutilada, sectorizada por una cuestión de género, ideológica o partidaria, reducida a un estatus casi tribal?

Ciertamente, así como se pretende reducir una ciencia a una expresión de un sector (las cultoras femeninas del conocimiento geográfico), buscando instalar una geografía "feminista", también la contrapartida es, entonces, igualmente legítima; es decir, la intención que los cultores masculinos pueden reivindicar para sí, tal vez pretendiendo una geografía "masculinista" (aunque esto suene paradójico y hasta risueño, pero que es atendible desde un meta-análisis de las intencionalidades y los discursos). ${ }^{x x x i}$

Necesitamos, por el contrario, una geografía plural, integradora y abierta, capaz de acoger la producción de conocimiento valioso generado tanto por la participación 
comprometida del género masculino como del género femenino ${ }^{\mathrm{xx} x i i}$, sin querer imponer una postura única que siempre resulta parcial y, ante todo, reduccionista y empobrecida del conocimiento científico.

Por este motivo, la tarea educativa que podemos realizar en estos momentos de crisis, de cambios sociales, de búsqueda de nuevas representaciones y modos de actuación es sumamente importante. La ciencia no es un partido político, ni puede ser reducida a ninguna actuación político-partidaria. Los propósitos de la ciencia tienen sí un fin social, pero fundado en el conocimiento riguroso, serio y confiable; en nuestro caso nos compete comprender y explicar la organización de los espacios geográficos: como escenarios, territorios y tramas de vida social y comunitaria. Necesitamos reflexionar acerca del valor del conocimiento geográfico: en qué medida estamos contribuyendo a gestar espacios geográficos más saludables, sustentables, inclusivos, ordenados, forjados en metas compartidas para la preservación de los recursos que ofrecen los lugares, los territorios; en las oportunidades de desarrollo humano que brindan las regiones, procurando construir relaciones socio-territoriales con criterios de equidad para los diferentes grupos humanos que habitan los escenarios de América Latina.

Estos asuntos son los que definirán la agenda compartida en un futuro cercano. El tiempo apremia, porque la existencia misma en nuestros espacios está comprometida... En consecuencia, no hay tiempo para distracciones. Es imprescindible y urgente poner todo nuestro empeño para educar en torno a los grandes desafíos que enfrentaremos en un futuro cercano en nuestra existencia "constreñida" a la superficie terrestre: un dominio denso de objetos tecnológicos, saturada de artefactos, sumamente artificializada y contaminada, territorialmente desequilibrada, donde hemos puesto en jaque la supervivencia de muchas especies y hasta nuestra propia continuidad como especie en el planeta.

En estos temas de fondo deberíamos estar ocupados y "trabajando laboriosamente", en lugar de implicarnos en "descender" hacia enredos discursivos que desvían el propósito del "conocer" científico. Nuestros alumnos que se forman para ser profesores, licenciados o gestores del territorio, del ambiente y de la administración responsable de los recursos escasos del espacio merecen que analicemos seriamente hacia dónde vamos al cultivar una ciencia: la geografía. Ellos, en tanto sujetos que están formándose con todas las herramientas cognoscitivas, técnicas y educativas para actuar en realidades complejas del mundo actual necesitan saber cuáles son los resortes de una ciencia, que les mostremos los fundamentos epistemológicos que subyacen en las investigaciones, que desnaturalicemos nuestros modus operandi (métodos de investigación) sin perder de vista los conceptos basales de nuestro campo de estudio, que les ayudemos a construir el auténtico pensamiento crítico, sustentado en valores y en criterios de razonabilidad propios a la hora de intervenir profesionalmente en la sociedad.

En suma, el tema de este ensayo es apenas un puntal para pensar estas cuestiones, pues la tarea que se nos avecina en este tema y en otros que se yerguen con fuerza en las sociedades del presente ameritan una reflexión fundamentada en principios, en ideas potentes cimentadas en conceptos científicos forjados en la larga evolución de nuestra ciencia, así como en valores humanos fundamentales y en el pensamiento libre (sin mordazas ni sujeción a ideologías vacías de contenido o sin razones consistentes). Los criterios morales son necesarios, tanto ayer como hoy, y quizás con más fuerza en la actualidad, para hacer frente a tantos desafíos que 
atraviesan y entroncan con el espacio geográfico como ámbito de vida, de superación humana, de salud física y mental, y de sustentabilidad de nuestra propia especie.

Al respecto, la pandemia del COVID-19 es un claro ejemplo de que nuestra existencia en el planeta (sin distinción de lugares) no es segura ni está garantizada, a la vez que anuncia que el espacio geográfico -el modo en que lo hemos construido y organizado (me refiero a los densos hormigueros humanos de las grandes ciudades y megalópolis actuales)- está en crisis y precisa ser re-pensado y re-construido. Pero, para esto, debemos tomar consciencia de que hay contenidos (temas) irrenunciables en los que hemos de concentrar nuestras energías.

\section{Conclusiones -para un debate abierto-}

Con este ensayo, alimentado por la búsqueda de argumentos desde la semiótica, las ciencias cognitivas y la epistemología, espero haber contribuido con ideas para la reflexión fundamentada sobre el cambio del nombre habitual con que se identifican los Encuentros EGAL en el contexto de la geografía que, como ciencia, no tiene fronteras ${ }^{x x x i i i}$-pues es una convergencia que define e identifica un dominio del saber científico- y constituye una totalidad compleja, cambiante y diversa de conocimientos plurales, protagonistas y prácticas investigativas...

Esta tarea de ensayar un nombre, proporcionar sus fundamentos y contraponerlo, reflexivamente, con otras posibles denominaciones, puede parecer una disquisición sobreabundante o hasta trivial; sin embargo, es preciso recordar la importante distinción -trabajada por Bateson (1993) ${ }^{\text {xxiv }}$ - entre el nombre y la cosa nombrada, o -desde un planteo semiótico- entre el signo (una palabra o una denominación) y aquello que es representado por éste. En efecto, el nombre no es la cosa nombrada, como el mapa no es el territorio, pero de alguna manera el nombre "configura" la cosa nombrada pues, en el universo específicamente humano, la construcción de la realidad está signada no sólo por la existencia "bruta" (de un mundo independiente, afuera, del sujeto) sino, "sobre todo", por la facultad de significarla, es decir, de "semiotizar"; por medio del lenguaje dotamos de "sentido" a la realidad: creamos realidad a través de las palabras. De ahí la preocupación por atisbar una denominación apropiada para los futuros Encuentros -a los que nos hemos referido- de manera que expresen su esencia genuina... un "nombre" amplio y pertinente al devenir de las sociedades y, a la vez, lo suficientemente preciso y atractivo para tener la fuerza convocante para reunir a quienes cultivan nuestra ciencia.

En este ensayo he planteado las dimensiones ontológicas, epistemológicas y semiótico-cognitivas que subyacen en los nombres, centrando la reflexión en los EGAL, pero tocando asuntos que incluso lo trascienden y haciéndolo en un contexto y circunstancias en que las tradiciones de las prácticas científicas (geográficas, en este caso) transitan por metamorfosis profundas. En dicho contexto, la "crítica interna" resulta imprescindible para volver a la esencia de la geografía como ciencia, clarificando lo que es del orden del objeto (el espacio geográfico) por diferenciación de otras cuestiones anidadas en la dimensión pragmática de los discursos -y lo que allí se encripta (contenidos ideológico-políticos, intencionales per se)- en los fenómenos comunicacionales del conocimiento geográfico.

Este trabajo de "develar" lo que está oculto, supuesto o latente es insoslayable en la cultura científica que experimentamos, donde, por un lado, se desvanecen los cánones rígidos, dogmáticos, y por otro, el horizonte que avizora se aleja de los 
fundamentos mismos de la ciencia (en pos de otras formas de conocimiento y prácticas sociales que nada tienen que ver con ella). Sin embargo, en tiempos posmodernos, de derrumbe de las creencias más firmes y de fugacidad de la experiencia humana, tal vez la tendencia sea hacia la fragmentación, donde cada grupo o sector, creyéndose "el saber" termine avalando una ciencia que sólo busque exhibir su pluralidad, sin ánimo de trascenderse a sí misma, conformándose con un sentido que se cierra en torno a las singularidades de ciertos contextos y prácticas.

Después de todo, tal vez el "hacer ciencia" sea visto como una meta trivial o, mejor dicho, circunscripta a un "quehacer tribal" (ceñido a significaciones particulares válidas en cierto grupo y contexto, pero vedado del esfuerzo por atisbar una universalidad iluminadora). Las palabras de Reynaud (1976), dichas hace ya más de cuarenta años, resultan muy pertinentes para entender el trasfondo:

La unidad de la geografía es, pues (...) un mito el cual procede ante todo de una interpretación etnológica. Lo mismo que para las poblaciones llamadas primitivas "la humanidad cesa en las fronteras de la tribu, del grupo lingüístico, o a veces incluso de la aldea", la "tribu" de los geógrafos ha puesto interés en afirmar su superioridad frente a las otras tribus científicas. Para mostrar mejor su originalidad, los geógrafos utilizan incansablemente los mismos argumentos, a pesar de que sus fundamentos epistemológicos no son muy seguros. Pero iqué importa!: en realidad dichos argumentos están con frecuencia destinados más a tranquilizar a los mismos geógrafos que a convencer a los especialistas escépticos 0 a un público indiferente. Esta autosatisfacción es irritante por su repetición, pero no tiene grandes consecuencias. (s/p.; las negritas son mías).

Es en esta encrucijada compleja, de discursos que se imponen por su redundancia semiótica y la conformación de nuevas tribus (discursivas, practicantes) situadas entre la dinámica académica y la cotidianidad, donde puede situarse este ensayo, como un aporte más a la reflexión para dirimir asuntos de los que, con frecuencia, no se habla o no se quiere tocar.

\section{Referencias bibliográficas}

AA.VV. (2019). "Pronunciamiento del Encuentro de Geografías Críticas y Autónomas" (dos págs.). Documento socializado en el marco de la Red de Geografía de Universidades Públicas Argentinas.

Austin, J. (1962). Cómo hacer cosas con palabras. Escuela de Filosofía Universidad ARCIS. http://revistaliterariakatharsis.org/Como hacer cosas con palabras.pdf

Bateson, G. (1993). Espíritu y naturaleza. Buenos Aires, Argentina: Amorrortu.

Benveniste, É. (1999). Problemas de lingüística general II. México D.F., México: Siglo Veintiuno Editores.

Carretero Bernal, F. (2005). "X Encuentro de Geógrafos de América Latina”. São Paulo, Brasil, 20 al 25 de marzo de 2005" (Noticias). Investigaciones Geográficas, Boletín 57, 150-152. 
Claval, P. (1999). La Geografía Cultural. Buenos Aires, Argentina: Eudeba.

Colombara, M. (2018). Geografía y género. Desde la geografía de las mujeres a la geografía de las sexualidades. En M. Colombara y otros. XII Jornadas Cuyanas de Geografía (pp.8-18). Mendoza, Argentina: Instituto de Geografía, Universidad Nacional de Cuyo.

Cuadra, D. (2014). Los enfoques de la geografía en su evolución como ciencia. Geográfica Digital, 11(21), 1-22. Recuperado de http://hum.unne.edu.ar/revistas/geoweb/default.htm

Chalmers, A. (1988). ¿Qué es esa cosa llamada ciencia? Bs. As., Argentina: Siglo Veintiuno Editores.

Eco, U. (2000). Tratado de semiótica general. Barcelona, España: Lumen.

EGAL. XVIII Encuentro de Geografías de América Latina. Circulares I y II. Recuperado de http://www.egal2021.org

Feyerabend, P. (1981). Tratado contra el método. Madrid, España: Tecnos.

Harvey, D. (1998). La condición de la posmodernidad. Investigación sobre los orígenes del cambio cultural. Bs. As., Argentina: Amorrortu.

Hegel, G.W.F. (2002). Fenomenología del Espíritu. México D.F., México: Fondo de Cultura Económica.

Herrera Restrepo, D. (2010). Husserl y el mundo de la vida. Franciscanum, LII (153), 247-274.

Husserl, E. (1962). Ideas <relativa a una fenomenología pura y una filosofía fenomenológicas. (Trad. de José Gaos). Bs. As., Argentina: Fondo de Cultura Económica.

Isaza Restrepo, E. (2013). Intencionalidad e imaginación. El problema de la referencia a las cosas. En G. Vargas Guillén y W. H. Silva Carreño (Eds.) La región de lo espiritual. En el centenario de la publicación de Ideas I de E. Husserl (pp. 217231). Bogotá, Colombia: Universidad Pedagógica Nacional.

Kant, M. (2007). Crítica de la razón pura. Trad. de Mario Caimi. Bs. As., Argentina: Colihue. [1 ${ }^{\text {a }}$ ed. alemana: 1781$]$.

Korzybski, A. (1994, Fifth Edition). Science and Sanity: An Introduction to NonAristotelian Systems and General Semantics. Brooklyn, New York, USA: Institute of General Semantics. [First Edition 1933].

Ladrière, J. (1978). El reto de la racionalidad. Salamanca, España: Sígueme-UNESCO.

Lebus, E. (2006). La Geografía en los últimos cincuenta años. Transformaciones metodológicas y su proyección en la práctica actual de la investigación. Boletín de GAEA 124, 4-31. 
Lebus, E. (2014). La noción de 'operatoria' como superación de la disyuntiva 'el método - los métodos' en geografía. Aportes reflexivos a partir de extractos de una tesis de maestría. Geográfica Digital, 11(22), 1-16. Recuperado de http://hum.unne.edu.ar/revistas/geoweb/default.htm

Lebus, E. (2017). Proyectar la tesis y encaminar la investigación. Bs. As., Argentina: Grupo de Escritores Argentinos.

Lythgoe, E. (2014). El papel de la imaginación en La memoria, la historia, el olvido de Paul Ricœur. Diánoia, 59(73). Recuperado de http://www.scielo.org.mx/scielo.php?script=sci_arttext\&pid=S0185-24502014000200004

Massey, D. (2005). For Space. London, England: Sage.

Morin, E. (2001). Los siete saberes necesarios para la educación del futuro. Bs. As., Argentina: UNESCO-Ediciones Nueva Visión.

Parret, H. (1993). Semiótica y Pragmática. Bs. As., Argentina: Edicial.

Peirce, Ch. (1970). Deducción, Inducción e Hipótesis. Bs. As., Argentina: Aguilar.

Peirce, Ch. (1987). Obra Lógico-semiótica. Madrid. España: Taurus.

Peirce, Ch. (1988). El hombre, un signo (El pragmatismo de Peirce). Trad., Intr. y Notas de José Vericat. Barcelona, España: Crítica. Recuperado de https://www.unav.es/gep/FixationBelief.html

Rey Balmaceda, R. (1974-75). La Geografía como forma de pensamiento. Boletín de GAEA 95, 1-9.

Reynaud, A. (1976). El mito de la unidad de la geografía. Geo Crítica, 1(2). Recuperado de http://www.ub.edu/geocrit/geo2.htm

Rojas Salazar, T. (2005). Epistemología de la Geografía... una aproximación para entender esta disciplina. Terra Nueva Etapa, XXI (30), 141-162. Recuperado de https://www.redalyc.org/pdf/721/72103006.pdf

Samaja, J. (1995). Epistemología y metodología. Elementos para una teoría de la investigación científica. Bs. As., Argentina: Eudeba.

Samaja, J. (2007). Las ciencias cognitivas como transdisciplina. Antinomicidades 0, 924. Resistencia: Facultad de Humanidades, Universidad Nacional del Nordeste.

Santos, M. (1996). Metamorfosis del espacio habitado. Barcelona, España: Oikos-tau.

Santos, M. (1997). La geografía a fines del siglo XX: nuevas funciones de una disciplina amenazada. En M. Santos y V. Di Cione, La geografía por venir. Cuestiones epistemológicas (pp. 7-30). Bs. As., Argentina: Cooperativa Editora Universitaria.

Soja, E. (2014). En busca de la justicia espacial. Valencia, España: Tirant Humanidades.

Tuan, Y. F. (1977). Space and place. The perspective of experience. Londres, Inglaterra: Arnold. 
RIIE (2021), Año 12 (15), 1-26.

DOI: http://dx.doi.org/10.30972/riie.12155565
Sobre el "Encuentro de Geógrafos de América Latina”. Ensayo de Aproximaciones Teóricas en torno a un Nombre.

\section{Notas}

${ }^{i}$ Morin, E. (2001). Cfr. Capítulo II: 'Principios de un conocimiento pertinente', pp. 35-46.

ii Artículo original de 1877 titulado: "The fixation of belief". Cfr. Peirce, 1988, pp. 175-199.

iii Esto es: los saberes provenientes de la vida misma, del ethos cultural de las comunidades, de las formas de reflexión de las sociedades con Estado y también de los procesos cognitivos propios de la ciencia. La dinámica misma del "proceso de investigación" recupera las distintas fuentes del saber (y el conocimiento entrañado en los sujetos partícipes) pero bajo una única Regla, que podemos enunciar así: que todo razonamiento y juicio valorativo acerca de lo que es verdadero sea referido al dictamen de la experiencia, lo que supone un modo de conocimiento (o método) que busca validarse por "algo externo" (al sujeto mismo), es decir, mediante la "constatación común" de "algo" (en la dimensión empírica del conocimiento), pero también por la validación de tales juicios cognoscitivos desde ciertas categorías conceptuales. Mientras lo primero remite a la existencia plena (hechos) lo segundo nos lleva a las teorías que los explican. iv Categoría que aborda como "representación" o "cartografiado" (entre hechos y conceptos).

$\checkmark$ Asuntos que Parret (1993) trata en: pp. 29-32 y pp. 42-44.

vi Sin embargo, también se pueden identificar posturas activistas anticapitalistas, neomarxistas, vinculadas a la reivindicación de tierras, la inclusión de las minorías, luchas ecologistas, etc. que, con nuevos o viejos ropajes, con frecuencia expresan un hilo conductor: una "instalación" cada vez más extendida del populismo en Latinoamérica.

vii No desconocemos desarrollos en esa dirección, pero la esencia de este ensayo es otra.

viii Efectivamente "es" un asunto "de fondo" aunque, en principio, "parezca ser" sin importancia.

ix Korzybski (1994) fundó una "semántica general" (distinta de la semántica), buscando así una fundamentación de la consciencia general de la abstracción humana que opera cuando nos relacionamos con el mundo, proceso en el cual las estructuras lingüístico-cognitivas juegan un papel clave, al intervenir como modelos o mapas mentales de acceso a la realidad.

x Nótese, empero, que aquí ya podemos advertir que una cosa es la reivindicación del rol de las cultoras del conocimiento geográfico (las geógrafas) y otra es el estudio de temas inherentes a la mujer y a otras categorías de género.

xi Al respecto, en la producción de este ensayo se analizó un escrito llegado desde la última reunión celebrada en Quito, 2019 (debatido asimismo en el Dpto. de Geografía de la UNNE). Se trata de una especie de "manifiesto" breve (dos págs.), pleno de lenguaje inclusivo y epítetos que banalizan el saber científico; documento que han dado en llamar: "Pronunciamiento del Encuentro de Geografías Críticas y Autónomas" (una especie de Encuentro paralelo al EGAL). xii Acaso, ¿se puede separar el conocimiento de quienes lo generan? Esto nos deja perplejos. xiii País que, por otra parte, fue la cuna de estos Encuentros, bajo el auspicio e impulso que le diera el destacadísimo geógrafo brasileño, Milton Santos, cuya labor trasciende Latinoamérica y alcanza relevancia mundial. Somos pues deudores de esa tradición.

xiv A pesar que en antropología -y en sociología- existe una tendencia similar. Esto es, confundir enfoques o tradiciones investigativas (algunas más acrisoladas y otras en desarrollo) con la ciencia misma, adonde convergen -no sin generar tensiones- la diversidad (de ideas) y la unidad (del corpus) en una totalidad "dialéctica" de saberes, praxis investigativas, marcos analíticos, etc. ${ }^{x v}$ Lo cual no significa que la ciencia geográfica sea monolítica, ni dogmática, sino, todo lo contrario: un saber plural, multifacético y muchas veces ecléctico. Este carácter fue tratado hace tiempo por Alain Reynaud (1976) en el sugerente artículo: "El mito de la unidad de la geografía". xvi Así, en otra época la geografía estudiaba toda la Tierra y luego se centró la mirada en la "superficie terrestre"; la corriente francesa, por su parte, interpretó que la "región" proporcionaba la visión sinóptica de los hechos geográficos y, desde mediados del siglo XX en adelante, fue asumiéndose -y aceptándose- el "espacio" como objeto de su interés.

xvii Cfr. Cuadra, Dante. (Enero-Junio 2014).

xviii Cfr. Lebus, Emilas. (Julio-Diciembre 2014).

xix Cfr. Lebus, Emilas. (2006).

xx Esta idea, desde otro ángulo y aplicada a la metáfora en la ciencia, fue trabajada por Humberto Magnasco en su Tesis de Maestría -que he dirigido- denominada "Bases epistémicas del surgimiento de la metáfora, como mecanismo de inteligencia, creación y comunicación en ciencias duras e ingeniería. Incidencia en la Docencia Universitaria" (UTN), donde desarrolla y 
RIIE (2021), Año 12 (15), 1-26.

DOI: http://dx.doi.org/10.30972/riie.12155565
Sobre el "Encuentro de Geógrafos de América Latina”. Ensayo de Aproximaciones Teóricas en torno a un Nombre.

fundamenta su principal conjetura de la génesis conjunta "Sujeto" y "Objeto" en las construcciones metafóricas que cimientan al conocimiento científico.

xxi La "imaginación productiva" recorre las obras de Paul Ricœur. La imaginación no es mero residuo de la percepción (como creían los empiristas), ni tampoco la negación de la percepción (como tendía a pensar la fenomenología, dado el papel de las vivencias) sino que ejerce una función clave en el conocimiento "como capacidad creativa y disruptiva" (Lythgoe, E., 2014).

xxii Nótese que, a diferencia de la historia que tiene res gestae (los hechos pasados, el acontecer histórico) y rerum gestarum (la historia, la comprensión o el relato de esos hechos, lo cual compete a la tarea del historiador / historiadora), la geografía versa sobre el conocimiento del espacio geográfico, es decir, refiere a la ciencia y no a su contenido material, fáctico o empírico. xxiii Aplicando la tesis kantiana, la geografía "implica" tanto la referencia a "hechos geográficos" (o a la espacialidad de tales hechos) como la "teorización" (o explicación) de esos hechos.

xxiv Como, por ejemplo, el destacado aporte de Egeria (o Etheria), la primera gran viajera mujer que, en el siglo IV d.C. -en tiempos de la decadencia del Imperio Romano-, recorriera las tierras bíblicas, abarcado Asia Menor, Mesopotamia, Jerusalén, Sinaí y Egipto, cuyos diarios de recorridos pasaron a ser, sin quererlo, el primer libro de viajes escrito por una mujer en sus periplos. Asimismo, la contribución al conocimiento geográfico de varias mujeres expedicionarias y exploradoras, adentradas en regiones recónditas o protagonistas de riesgosos viajes en épocas en que la labor investigativa-cultural de la mujer no era reconocida y, casi siempre, mal vista.

${ }^{x x v}$ En última instancia, podemos incluso denominar a este evento "Encuentro Latinoamericano de Geografía" (aun cuando implicaría una nueva sigla); sería muy pertinente para destacar la ciencia que se hace desde nuestro continente, enriqueciendo una única ciencia (la geografía).

xxvi Un "Encuentro de Profesionales..." expresa la esencia del evento que nos ocupa, tipificado como "Encuentro". Esta misma palabra incluye todo (el diálogo, el intercambio entre distintos sujetos cognoscentes) como parte del acuerdo. Es imposible -ni siquiera pensar- un Encuentro cuyo eje no pivotee en las personas.

xxvii Línea de trabajo que anticiparon -hace ya dos décadas atrás- destacados estudiosos en el campo geográfico, como Paul Claval (1999), David Harvey (1998), Milton Santos (1996, 1997), Yi Fu Tuan (1977), Doreen Massey (2005) y Edward Soja (2014), entre otros.

xxviii El criticismo es una postura desviada por el énfasis concedido al lugar del "intérprete" en el proceso semiótico. Si bien el "interpretante" sígnico (o Regla) remite, en su historia constructiva, al papel de los intérpretes, pues en la sociabilidad del signo emanan y se validan determinadas reglas "asumidas" como interpretantes, cuando uno de los componentes del signo -de la triádica peirceana- es enfatizado en desmedro de los otros dos surgen aquellas desviaciones de las que habla Parret (op. cit., 1983), a saber: sintacticismo, semanticismo, pragmaticismo, y hasta, semioticismo. El criticismo es consecuencia directa del pragmaticismo.

${ }^{x x i x}$ Resulta muy llamativo los nuevos ropajes que adquieren los conceptos: para decir lo mismo se usan epítetos desconocidos, rimbombantes, atractivos (palabras novedosas), aunque en el fondo remiten a los mismos significados, pero con el agravante de suscitar interpretaciones ambiguas y de "instalar un sentido" que atrapa por la fuerza con que irrumpe.

xxx Es preciso subrayar que una ciencia nunca es obsoleta, ni banal. No se puede menospreciar ni desvalorizar la "historia" de una disciplina (sus teorías, sus autores y sus saberes acumulados) porque ella representa los "cimientos", sin los cuales no habría posibilidad alguna de nuevo conocimiento, pues ningún conocimiento, ni en la ciencia ni en la vida cotidiana, surge de la nada. Todo conocimiento "actual", aunque parezca "el saber más logrado", siempre deviene de un "saber previo", producto en una vasta y milenaria génesis formativa (de la geografía, en este caso) a partir del encadenamiento de las ideas y su decantación; esto es válido aun cuando ese saber haya surgido de luchas, revoluciones, dominaciones, etc. Siempre se trata de un proceso evolutivo y autorregulado: esto es precisamente jun "sistema complejo"!

xxxi De hecho, toda postura que busque llevar a un "extremo" cierta realidad (por ejemplo, la crítica a las formas "espaciales" androcéntricas que han organizado los territorios) para reivindicar el rol de la mujer en la construcción de los espacios -hecho que no es nuevo-) instala una mirada sesgada de la ciencia que, como tal, es acreedora de toda su historia formativa e integradora de todas las posturas. De hecho, la geografía crítica (o "radical" en su vertiente más acentuada) no es más que una parte de una totalidad más integradora: la geografía como ciencia. Y, por un principio de los sistemas complejos, la totalidad es más que la suma de las partes. 
RIIE (2021), Año 12 (15), 1-26.

DOI: http://dx.doi.org/10.30972/riie.12155565
Sobre el "Encuentro de Geógrafos de América Latina”. Ensayo de Aproximaciones Teóricas en torno a un Nombre.

xxxii $Y$ de cualquier forma en que se exprese el género del ser humano.

xxxiii En consecuencia, sería impropio aludir a las "geografías"-con o sin mayúscula- de América Latina; la razón radica en el saber sistemático, coherente y plural de nuestra ciencia, y en la imposibilidad de confundir su objeto de estudio (el espacio) con las realidades materiales (hechos geográficos, motivo del interés cognoscitivo).

xxxiv Distinción que Bateson trató en las "tipologías lógicas" (Cfr. Bateson, G., 1993) y, desde la semiótica, Umberto Eco aborda esta cuestión que recorre su pensamiento (Cfr. Eco, U., 2000). 